\title{
THE ROLE OF THE TRACTUS DIAGONALIS IN DRINKING BEHAVIOUR INDUCED BY CENTRAL CHEMICAL STIMULATION, WATER DEPRIVATION AND SALT INJECTION*
}

\author{
G. K. Terpstra and J. L. Slangen \\ Rudolf Magnus Institute for Pharmacology, Medical Faculty, University of Utrecht, \\ Vondellaan 6, Utrecht, The Netherlands
}

(Accepted 16 March 1972)

\begin{abstract}
Summary - The role of the tractus diagonalis in drinking behaviour induced by central chemical stimulation, 23-hr water deprivation and injection of a hypertonic sodium chloride solution was investigated by means of central and peripheral administration of atropine and methylatropine. The effect of the same doses of centrally and peripherally administered anticholinergics was greater on carbachol-induced drinking than on deprivation-induced drinking. Salt-induced drinking was only influenced by peripheral administration of the anticholinergics.

The results indicate the presence of a central cholinergic and a peripheral cholinergic active mechanism in carbachol-induced drinking; a central cholinergic, a peripheral cholinergic and a non-cholinergic mechanism in deprivation-induced drinking; and a central cholinergic, a peripheral cholinergic and a non-cholinergic mechanism in salt-induced drinking. It is concluded that a cholinergic system cannot be the system that has an overall control over water intake behaviour. The results obtained make it questionable whether the tractus diagonalis has a specific function in the series of events that lead to water intake after water deprivation or a salt injection.
\end{abstract}

IT IS known that local administration of cholinergic substances like carbachol in the limbic system can elicit drinking in satiated rats (Grossman, 1960, 1962a; FISHFr and Coury, 1962). In experiments concerning the nature of the transmission system involved it appeared that administration of atropine and methylatropine in the limbic system inhibited drinking induced by carbachol stimulation (Grossman, 1962b, 1964; STEIN and SEIFTER, 1962; LEVITT and FISHER, 1966). It was further demonstrated that the effects of atropine and methylatropine on carbachol-induced drinking were not significantly different when both substances were administered in the tractus diagonalis (TER PSTRA and SLANGEN, 1972).

From these brain stimulation and blocking studies the existence of a central cholinergic system may be inferred. The significance of this system in drinking behaviour induced by stimuli other than carbachol (e.g. deprivation) has not yet been investigated systematically. Evidence has been presented that there are differences between carbachol-induced drinking and deprivation-induced drinking (KRIKSTONE and LEVITT, 1970) and between carbacholinduced drinking and drinking induced by injection of a hypertonic salt solution (LEVITT and BUERGER, 1970). In order to clarify these differences we decided to determine whether the inhibiting action of centrally administered atropine and methylatropine on drinking was different for these three types of drinking behaviour.

*The research reported in this article was supported by the Netherlands Organization for the Advancement in Pure Research (Z.W.O.). 
For the evaluation of the results obtained from the experiments mentioned above it is necessary to investigate the inhibiting action of systemically administered atropine and methylatropine on drinking caused by the different dipsogenic stimuli since systemically administered atropine also inhibits carbachol-induced drinking (Grossman, 1962b, 1964; STEIN, 1963).

\section{METHODS}

Male albino rats of an inbred Wistar strain were used. The animals were housed individually in wire cages under conditions of ad lib. food (Muracon I pellets) and tap water (except in the water deprivation experiments). The environmental temperature was $22 \pm 2^{\circ} \mathrm{C}$ and a light was on from 5 a.m. until 7 p.m.

Cannulae were implanted stereotactically in the tractus diagonalis of rats in which drugs were administered centrally. Before each test the animals were weighed. The test cages were identical to the home cages. In order to reduce the interaction between food and water intake, food was not available during drinking tests. The same test was performed at least 3 times except in cases especially mentioned. Between two tests there was at least a 48-hr interval, firstly to make sure that the animal had returned to a normal physiological condition and secondly to exclude as much as possible a prolonged effect of the drugs. Because an effect of methylatropine is demonstrable after $24 \mathrm{hr}$ (GERALD and MAICKEL, 1969), a $72 \mathrm{hr}$ interval was used in tests in which methylatropine was administered.

\section{Drugs}

The drugs administered were carbachol (carbamylcholine-chloride), atropine sulphate, and atropine methylnitrate. For injection the drugs were dissolved in saline.

\section{Histology}

After termination of the experiments the rats in which a cannula had been implanted were perfused under deep nembutal anaesthesia with saline and buffered $10 \%$ formalin (pH 7.0). The brains were removed and stored in $10 \%$ formalin solutions. Frozen sections were cut $(100 \mu)$ and stained with oil red $O$ and Harris' haematoxylin. The stimulation sites were microscopically determined by comparing the series of sections in front of, through and behind the lowest part of the cannula track.

\section{Statistical evaluation}

For statistical evaluation of the results $t$-tests for difference between the means of two samples, with an F-test for equality of variances, were used. In case of an inequality of the variances degrees of freedom were adjusted according to Welch (DE JONGE, 1964).

\section{EXPERIMENT I}

The cffects of peripherally and centrally administered atropine and methylatropine on the water intake induced by carbachol stimulation of the tractus diagonalis.

\section{Methods}

A. Peripheral administration of atropine and methylatropine. In 6 rats, mean weight $314 \mathrm{~g}$, a cannula was implanted stereotactically under nembutal anaesthesia. The tip of the cannula was aimed at the tractus diagonalis. Co-ordinates with respect to the bregma were 
lateral: $0.3 \mathrm{~mm}$, anterior: $1.7 \mathrm{~mm}$ and depth: $6.6 \mathrm{~mm}$ (ALBE-Fessard, Stutinsky and LiBoubAN, 1966). The cannula was anchored to the skull by stainless steel screws and cement. After the rats reached their preoperative weight, tests were performed as follows:

Rats were injected i.p. with atropine $(10 \mathrm{mg} / \mathrm{kg})$ or methylatropine $(9.52 \mathrm{mg} / \mathrm{kg}$. After half an hour in which it was possible to check the animal's water intake as a result of the handling and the injection, the animals were injected intracerebrally with $7 \cdot 2 \mathrm{nmol}$ of carbachol $(1 \cdot 2 \mu \mathrm{g})$. The water intake in $1 \mathrm{hr}$ as a result of the carbachol injection was read off the calibrated drinking tube to the nearest $0.1 \mathrm{ml}$. When rats were injected i.p. with saline and drank less than $5 \mathrm{ml}$ of water in the hour after the carbachol injection, they were considered nondrinkers and discarded from the experiment.

Control values of the water intake were obtained from the tests in which saline (i.p.) and intracerebral carbachol were injected. Control experiments were performed with all rats in a randomized order before and after their atropine or methylatropine tests.

B. Central administration of atropine and methylatropine. In two groups of 6 rats, mean weight $195 \mathrm{~g}$ and $292 \mathrm{~g}$, a cannula was implanted in the tractus diagonalis as described above.

The first group was used for the testing of the blocking action of atropine. At the start of the test the cannula was opened and the stylus taken out of the cannula, cleaned and returned in place after administration of $1.3 \mathrm{nmol}$ of atropine (dissolved in $1 \mu \mathrm{l}$ saline), or in the case of a control test, after a mock injection. After half an hour in which it was possible to check the animal's water intake as a result of the handling and the atropine injection or the mock injection, the cannula was opened again and the animal was injected with $7 \cdot 2$ nmol of carbachol. After closing the cannula the water intake in the next hour was read off the calibrated drinking tube to the nearest $0.1 \mathrm{ml}$. The water intakes of the rats given a mock injection and $7 \cdot 2 \mathrm{nmol}$ carbachol were considered control water intakes.

The same test was performed with the second group of 6 rats except that in this case methylatropine was administered instead of atropine.

\section{Results}

In the first part of the experiment one animal at first did not reach the criterion of more than $5 \mathrm{ml}$, later on it appeared to be a drinker. The results obtained with this rat are partly used in Figure 1. Histological examination revealed an incorrect cannula placement in one animal; the results obtained from this rat are not used in Figure 1. Figure 1 (upper part) shows that atropine and methylatropine, at a dose of 10 and $9.52 \mathrm{mg} / \mathrm{kg}$ have approximately the same effect on water intake after injection of $7 \cdot 2 \mathrm{nmol}$ of carbachol, i.e. the water intake was nearly completely inhibited. There is no significant difference in the percentage of inhibition by atropine and methylatropine $(P>0 \cdot 2, t=1 \cdot 0336, \mathrm{df}=7 \cdot 0)$. The mean water intake in the control tests was, for the "atropine rats", $15 \cdot 2 \mathrm{ml}$ and, for the "methylatropine" rats, $15 \cdot 6 \mathrm{ml}$.

In the second part of experiment 1 , one rat was discarded from the atropine group because it was a nondrinker. Wrong cannula placement in the methylatropine group was found in one animal. The results obtained from these rats are not used in Fig. 1. Carbachol-elicited drinking was also inhibited completely by centrally administered atropine and methylatropine at a dose of $1.3 \mathrm{nmol}$ (Fig. 1, lower part). Here too, no significant difference between the percentage of inhibition by atropine and methylatropine was found $(P>0 \cdot 5, t=0 \cdot 5860$, $\mathrm{df}=8 \cdot 0$ ). Water consumption in the control tests was, for the atropine group, $7.7 \mathrm{ml}$ and, for the methylatropine group, $16.1 \mathrm{ml}$. This difference can be attributed for the greater part to the differences in body weight of the experimental animals. A positive correlation 


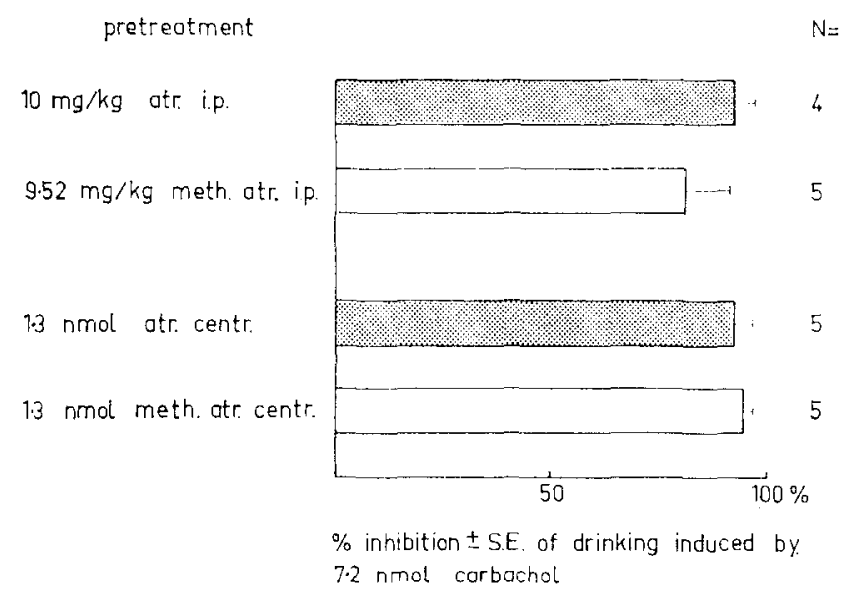

FIG. 1. The percentage of inhibition ( \pm S.E.) of drinking induced by $7 \cdot 2 \mathrm{nmol}$ of carbachol.

was found between the body weight of the rats and the water intake as a result of the first injection of carbachol (SPEARMAN rank correlation test (DE JONGE and WIELENGA, 1963): $t=2 \cdot 77, P=0 \cdot 00560$ ). Figure 2 shows the regression line of the water intake on the body weight $(\mathrm{y}=0 \cdot 057 \mathrm{x}-8 \cdot 3)$.

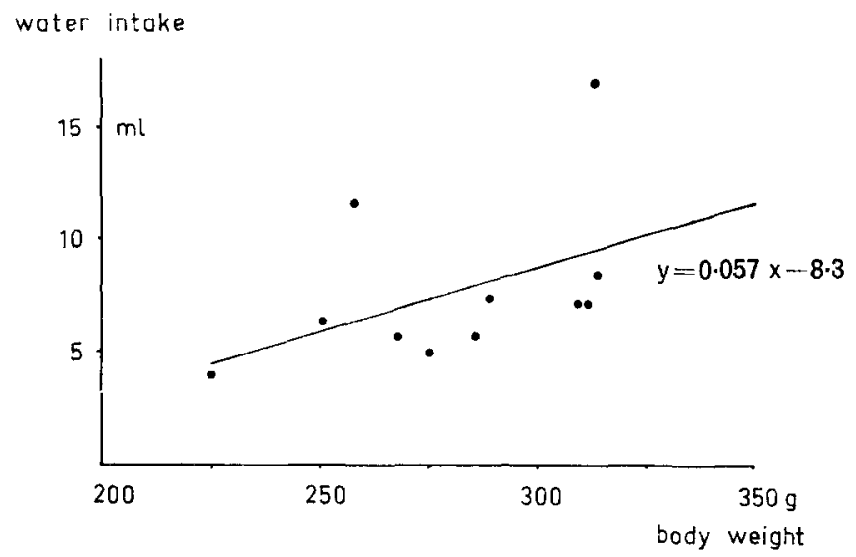

FIG. 2. The regression line estimating from the body weight (range $225-314 \mathrm{~g}$ ) the water iutake as a result of the first carbachol injection.

\section{EXPERIMENT II}

The effects of peripherally and centrally administered atropine and methylatropine on the water intake induced by a $23 \mathrm{hr}$ water deprivation schedule.

\section{Methods}

A. Peripheral administration of atropine and methylatropine. Three groups of rats, mean weight 237,230 and $220 \mathrm{~g}(\mathrm{n}=12, \mathrm{n}=8$, and $\mathrm{n}=8)$, were water deprived according to a 23-hr water deprivation schedule. After the daily 1-hr water intake had been stabilized the animals were tested. Five min before the $1 \mathrm{hr}$ drinking test atropine was injected i.p. in a 
dose of 10,25 and $50 \mathrm{mg} / \mathrm{kg}$ respectively or methylatropine in a dose of $9 \cdot 52,23 \cdot 8$ and $47 \cdot 6$ $\mathrm{mg} / \mathrm{kg}$ respectively. Each group of rats received only one dose of atropine and the equimolar dose of methylatropine. The atropine and methylatropine injections were given randomly. The daily $1 \mathrm{hr}$ water intakes on the days before test days were considered control water intakes.

B. Central administration of atropine and methylatropine. In two groups of rats, mean weight 286 and $314 \mathrm{~g}(\mathrm{n}=6$ and $\mathrm{n}=8)$, a cannula was implanted into the tractus diagonalis as described earlier. After reaching preoperative weight the animals were pretested with an intracerebral injection of $7 \cdot 2 \mathrm{nmol}$ of carbachol. Provided that the rats responded with a good drinking behaviour, they were subsequently accustomed to a $23 \mathrm{hr}$ water deprivation schedule. After stabilization of the water intake the rats were injected intracerebrally 5 min before the daily $1 \mathrm{hr}$ drinking test with $1.3 \mathrm{nmol}$ of atropine (the first group) or with 1.3 nmol of methylatropine (the second group). The daily $1 \mathrm{hr}$ water intake on days before test days was considered the control water intake.

\section{Results}

Figure 3 (upper part) shows that i.p. administration of atropine inhibited the water intake induced by a $23 \mathrm{hr}$ water deprivation at the $30 \%$ level. The differences in percentage inhibition between the lowest dose and the higher doses used were not significant $(10 \mathrm{mg} / \mathrm{kg}$ cf. $25 \mathrm{mg} / \mathrm{kg}: P>0.9, t=0.0923$, df $=18.0 ; 10 \mathrm{mg} / \mathrm{kg}$ cf. $50 \mathrm{mg} / \mathrm{kg}: P>0.5, t=0.5471$, $\mathrm{df}=18 \cdot 0$ ). Methylatropine inhibited the water intake at the $20 \%$ level. The difference in percentage inhibition between the doses of 9.52 and $23.8 \mathrm{mg} / \mathrm{kg}$ was not significant $(P>0.5$, $t=0.2259, \mathrm{df}=18 \cdot 0$ ). The difference in percentage inhibition between doses of 9.52 and $47.6 \mathrm{mg} / \mathrm{kg}$ was significant $(P<0 \cdot 02, t=2 \cdot 6617$, df $=18 \cdot 0)$.

The mean water intake in control tests was $14 \cdot 3,12 \cdot 3$ and $13 \cdot 7 \mathrm{ml}$ respectively for the groups in which doses of 10,25 and $50 \mathrm{mg} / \mathrm{kg}$ of atropine were administered. For the groups in which doses of $9.52,23.8$ and $47.6 \mathrm{mg} / \mathrm{kg}$ of methylatropine were administered the mean water intake in control tests was $14 \cdot 4,12 \cdot 6$ and $12 \cdot 5 \mathrm{ml}$ respectively.

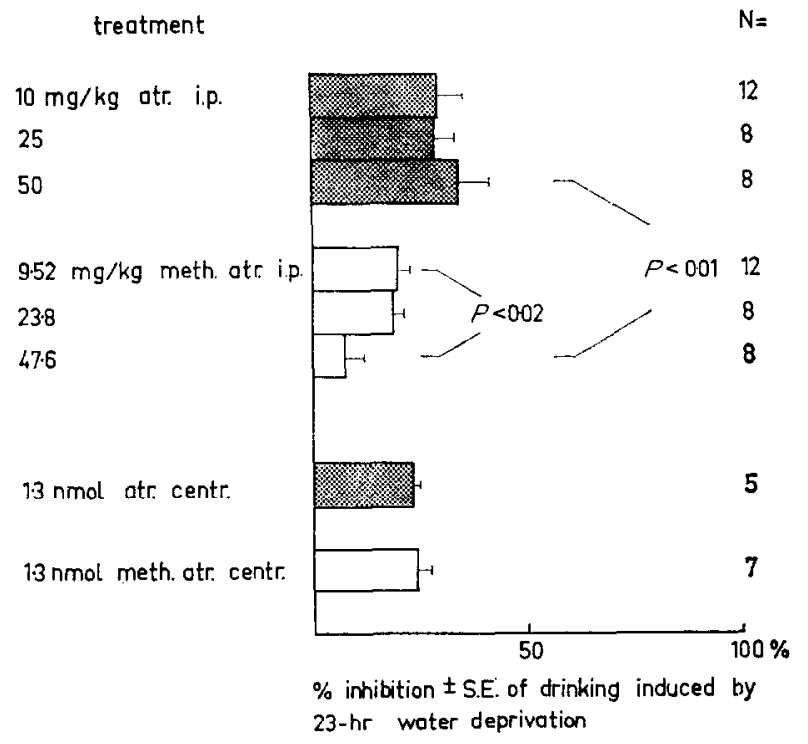

FIG. 3. The percentage of inhibition (土 S.E.) of drinking induced by 23-hr water deprivation. 
The differences in percentage inhibition by atropine and methylatropine at the same dose levels were not significant for the two lower doses $(10 \mathrm{mg} / \mathrm{kg}$ of atropine cf. $9.52 \mathrm{mg} / \mathrm{kg}$ of methylatropine: $P>0 \cdot 1, t=1.5947, \mathrm{df}=15 \cdot 5049,25 \mathrm{mg} / \mathrm{kg}$ of atropine $\mathrm{cf} .23 .8 \mathrm{mg} / \mathrm{kg}$ of methylatropine: $P>0.05, t=1.9455, \mathrm{df}=14.0)$. The difference in percentage inhibition by atropine and methylatropine at the highest dose was significant $(P<0 \cdot 01, t=3 \cdot 3132, \mathrm{df}=$ $14 \cdot 0$ ).

In the second part of the experiment the effect of centrally administered atropine and methylatropine $(1.3 \mathrm{nmol})$ was tested on deprivation-induced water intake in two groups of rats. In one animal of each group the cannula was misplaced. The results obtained with these rats are not included in the following data and in Figure 3. All the remaining rats demonstrated a good drinking response after intracerebral injection of $7.2 \mathrm{nmol}$ of carbachol. The mean water intake induced by carbachol stimulation was 15.6 and $12.1 \mathrm{ml}$ respectively for both groups. Atropine and methylatropine inhibited the water intake induced by deprivation about equally (Fig. 3, lower part). The difference in percentage inhibition was not significant $(P>0 \cdot 5, t=0 \cdot 1720, \mathrm{df}=7 \cdot 0889$ ). The control water intake amounted to $20.5 \mathrm{ml}$ for the atropine group and to $21.0 \mathrm{ml}$ for the methylatropine group. In both groups the water intake did differ significantly from control water intake (atropine: $P<0 \cdot 01, t=3 \cdot 5189, \mathrm{df}=8 \cdot 0$; methylatropine: $P<0.01, t=4 \cdot 5222$, $\mathrm{df}=7 \cdot 8464$ ).

\section{EXPERIMENT III}

The effect of peripherally and centrally administered atropine and methylatropine on the water intake induced by subcutaneous administration of a hypertonic $\mathrm{NaCl}$ solution.

\section{Methods}

A. Peripheral administration of atropine and methylatropine. Three groups of rats, mean weight 303,323 and $327 \mathrm{~g}(\mathrm{n}=12, \mathrm{n}=9$ and $\mathrm{n}=9)$, were injected s.c. with $1 \cdot 2 \mathrm{ml}$ of a $15 \% \mathrm{NaCl}$ solution. In order to prevent pain associated with the salt injection the solution contained $2 \cdot 4 \%$ procaine hydrochloride (WAYNER, Ross and PRIEN, 1964).

In pilot experiments we observed that after the second salt injection the water intake during the 2 hours after an injection was reproducible. The rats were injected not more than twice a week. Five minutes before the third salt injection the rats were injected with atropine $(10,25$ or $50 \mathrm{mg} / \mathrm{kg}$ i.p.) or with methylatropine $(9 \cdot 52,23.8$ or $47.6 \mathrm{mg} / \mathrm{kg}$ i.p. $)$ or with saline ( $2 \mathrm{mg} / \mathrm{kg}$ i.p.). Subsequently the animals were injected with the $15 \% \mathrm{NaCl}$ solution and the water intake in the next $2 \mathrm{hr}$ was measured to the nearest $0.1 \mathrm{ml}$. The intake of the rats injected i.p. with saline and subsequently with $15 \% \mathrm{NaCl}$ s.c. was considered control water intake. Each group was tested in a randomized order with one dose of atropine, with the equimolar dose of methylatropine and with saline.

B. Central administration of atropine and methylatropine. In one group of rats, mean weight $294 \mathrm{~g}(\mathrm{n}=8)$, a cannula was implanted in the tractus diagonalis as described earlier. After reaching their preoperative weight the rats were pretested with $7 \cdot 2 \mathrm{nmol}$ of carbachol in order to establish that they were good drinkers. Subsequently they received two salt injections s.c. with a $72 \mathrm{hr}$ interval.

In the tests the rats received $1.3 \mathrm{nmol}$ of atropine or methylatropine intracerebrally, or they received mock injections. After $5 \mathrm{~min}$ they were injected with the salt solution. The water intake in the next $2 \mathrm{hr}$ was measured to the nearest $0.1 \mathrm{ml}$. Atropine, methylatropine and the mock injections were given in a randomized order. Each rat was tested in each of the 
three conditions once. The water intake of rats intracerebrally given a mock injection and subsequently a salt injection was considered as control intake.

\section{Results}

Figure 4 (upper part) shows that i.p. administration of atropine inhibited the water intake induced by a salt injection by about $45 \%$. The differences in percentage inhibition at the doses used were not significant $(10 \mathrm{mg} / \mathrm{kg}$ cf. $25 \mathrm{mg} / \mathrm{kg}: P>0 \cdot 4, t=0 \cdot 7279, \mathrm{df}=19 \cdot 0 ; 10$ $\mathrm{mg} / \mathrm{kg}$ cf. $50 \mathrm{mg} / \mathrm{kg}: P>0 \cdot 5, t=0.5307, \mathrm{df}=19 \cdot 0)$. Contrary to the results obtained with atropine, graded doses of methylatropine gradually inhibited the water intake. At the dose of $9.52 \mathrm{mg} / \mathrm{kg}$ no inhibition was demonstrated, while at the dose of $47.6 \mathrm{mg} / \mathrm{kg}$ the inhibition rose to $55 \%$. At the lower doses the difference in percentage inhibition was not significant $(9.52 \mathrm{mg} / \mathrm{kg}$ cf. $23.8 \mathrm{mg} / \mathrm{kg}: P>0 \cdot 1, t=1.4788, \mathrm{df}=19 \cdot 0)$. The blocking action obtained with the highest dose differed significantly from the lowest dose $(10 \mathrm{mg} / \mathrm{kg} \mathrm{cf} .47 .6 \mathrm{mg} / \mathrm{kg}$ : $P<0 \cdot 001, t=4 \cdot 1186, \mathrm{df}=19 \cdot 0$ ).

The differences in the inhibitory action of atropine and methylatropine at the same dose levels was only significant at the lowest doses $(10 \mathrm{mg} / \mathrm{kg}$ of atropine $\mathrm{cf} .9 .52 \mathrm{mg} / \mathrm{kg}$ of methylatropine: $P<0.005, t=2.2934, \mathrm{df}=22.0 ; 25 \mathrm{mg} / \mathrm{kg}$ of atropine $\mathrm{cf} .23 .8 \mathrm{mg} / \mathrm{kg}$ of methylatropine: $P>0 \cdot 2, t=1 \cdot 0302, \mathrm{df}=16 \cdot 0 ; 50 \mathrm{mg} / \mathrm{kg}$ of atropine $\mathrm{cf} .47 .6 \mathrm{mg} / \mathrm{kg}$ of methylatropine: $P>0 \cdot 5, t=0.6476, \mathrm{df}=16 \cdot 0$ ).

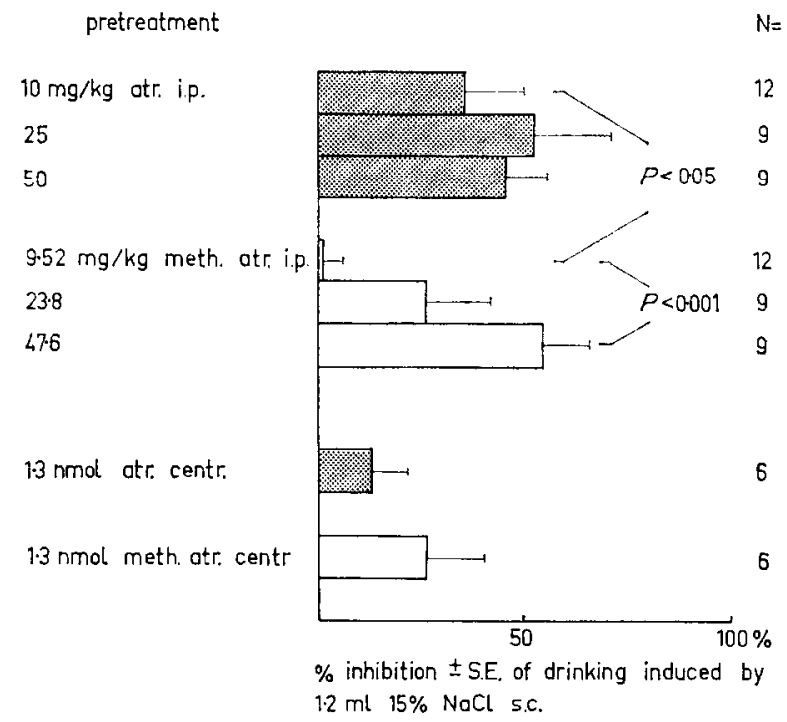

FIG. 4. The percentage of inhibition ( \pm S.E.) of drinking induced by a subcutaneous injection of $1 \cdot 2 \mathrm{ml}$ of a $15 \% \mathrm{NaCl}$ solution.

The mean water intake in control tests was for the " $10 \mathrm{mg} / \mathrm{kg}$ group" $10.4 \mathrm{ml}$, for the " 25 $\mathrm{mg} / \mathrm{kg}$ group" $11.3 \mathrm{ml}$ and for the "50 $\mathrm{mg} / \mathrm{kg}$ group" $12.7 \mathrm{ml}$.

In the second part of the experiment the effect of intracerebrally injected atropine and methylatropine $(1.3 \mathrm{nmol})$ was tested. All rats in this group responded well after intracerebral injection of $7.2 \mathrm{nmol}$ of carbachol, although in two animals the cannula was not located exactly inside the diagonal band.

The results of these two rats are omitted from the following data and Figure 4 (lower part). 
For the remaining animals the mean water intake induced by carbachol stimulation was $11.0 \mathrm{ml}$. The water intake induced by a salt injection which was preceded by the intracerebral injection of atropine and methylatropine was not significantly different from control water intake (atropine: $P>0.4, t=0.7983, \mathrm{df}=10.0$; methylatropine: $P>0.05, t=1.8954$, $\mathrm{df}=10 \cdot 0)$.

The difference between the effects of atropine and methylatropine was not significant $(P>0 \cdot 4, t=0 \cdot 7775, \mathrm{df}=10 \cdot 0)$. The mean water intake in control tests was $10 \cdot 2 \mathrm{ml}$.

\section{Histological results}

Brain sections of all cannulated animals were examined. Except in the cases mentioned below the cannula was always found in the tractus diagonalis, generally just in front of and below the commissura anterior. Sometimes the placements were a little posterior in the commissura anterior, but because of the width of the cannula, the cannula also reached into the tractus diagonalis.

In experiment I A the cannula in one rat was placed partly in the nucleus preopticus medialis and partly in the tractus diagonalis. After the first carbachol injections the animal did not drink. Later on it appeared to be a drinker and we assume that the cannula was obstructed until then. From a second animal (a drinker) no histology was available. In experiment I B, in one rat of the atropine group, the cannula was placed in the nucleus preopticus medialis. The animal did not drink. For one animal of the methylatropine group (a drinker) no histology was available.

This also was the case for one rat of the atropine group in experiment II B (a drinker). The cannula in one rat of the methylatropine group (a drinker) was placed in the nucleus preopticus medialis near the tractus corticohypothalamicus medialis and the nucleus hypothalamicus anterior. In experiment III B no histology was available for the identification of the cannula placement in two rats (both drinkers).

\section{DISCUSSION}

\section{Peripheral administration of atropine and methylatropine}

From the results of experiment I we concluded that the area for the elicitation of centrallyinduced drinking and centrally-induced inhibition was well selected in relation to the problems to be studied. Drinking induced by carbachol stimulation of the tractus diagonalis could be inhibited by systemic administration of atropine and methylatropine. In both cases the drinking response was almost completely blocked and no difference in the inhibiting action of atropine and methylatropine was observed. Assuming the impermeability of the blood-brain barrier to methylatropine (HERZ, TESCHEMACHER, HoFSTETTER and KuRZ, 1965; KHAVARI and MAICKEL, 1967), it is striking that systemically administered methylatropine is not only able to inhibit centrally induced drinking but is as potent as atropine in this respect. The possibility that the effect of methylatropine is the result of conversion of methylatropine into atropine is unlikely because it has been shown that methylatropine is still active $24 \mathrm{hr}$ after administration, while under the same conditions the effect of atropine is not demonstrable (Gerald and MaICKEL, 1969; Khavari and Russell, 1969).

In view of the foregoing, several interpretations are possible. It may be that the signal evoked by the central stimulation is detected by means of a peripheral cholinergic system. Secondly, it may be possible that atropine and methylatropine interfere with peripheral processes necessary for the performance of water intake. For instance, intraperitoneal administered atropine is known to enhance motor activity in the rat (HEISE and BOFF, 1971), 
and in the mouse (FrancES and JACOB, 1971). Thirdly, the possibility cannot be ruled out that a very small amount of methylatropine passes the blood-brain barrier and blocks the water intake by means of a central cholinergic system.

In the second experiment drinking behaviour induced by water deprivation was inhibited by not more than $35 \%$ by peripherally administered atropine and methylatropine. Again we have to consider several possibilities, The fact that in the lower dose range both atropine and methylatropine inhibited the water intake equally may point to the possibility that the signal evoked by the water deprivation is processed by a peripheral cholinergic system, at least if we assume that methylatropine does not reach the brain. However, at the highest dose atropine was more effective than methylatropine and therefore we must consider the possibility that in this case atropine influences a peripheral as well as a central cholinergic pathway (perhaps belonging to the same system). Thirdly, it may be possible that atropine and methylatropine interfere with processes (centrally and/or peripherally) underlying the performance of water consumption. Fourthly, since even very high doses of anticholinergics cannot inhibit the drinking completely, we have to infer the existence of a non-cholinergic mechanism co-regulating water intake.

In earlier reports, in which a peripheral cholinergic component was also postulated in deprivation-induced water consumption the percentage of inhibition in fact rose to about $40 \%$ (atropine and methylatropine, $2 \cdot 5,5$ and $10 \mathrm{mg} / \mathrm{kg}$, GerALD and MAICKEL, 1969) and to about $60 \%$ (atropine and methylatropine, 1,10 and $20 \mathrm{mg} / \mathrm{kg}$, KHAVARI and RuSSELL, 1969). In our experiment the percentage inhibition was $35 \%$ maximally for atropine and $20 \%$ maximally for methylatropine. The differences in inhibition obtained by the various authors are difficult to explain. Motivational effects, due to different bodily requirements and taste factors, are likely however. Whichever dose of atropine or methylatropine was used the minimum water intake was always at least about $9 \mathrm{ml}$. From our results, as well as from the results of Gerald and MaICKel. (1969) and KHAVARI and RusSell (1969), it appears that it is very difficult to reduce the water intake to less than $9 \mathrm{ml}$ in deprivation-induced drinking by systemic administration of the anticholinergics. This suggests the involvement of a noncholinergic mechanism in the regulation of water intake.

Drinking induced by a subcutaneous injection of a hypertonic $\mathrm{NaCl}$ solution was inhibited equally by graded doses of peripherally administered atropine by about $50 \%$. On the other hand graded doses of methylatropine gradually inhibited the water intake up to a $55 \%$ level. If we accept that methylatropine cannot pass the blood-brain barrier the results obtained with the lowest dose of atropine and methylatropine point to the presence of a central cholinergic system. However, the results obtained with the highest dose, where the inhibition of the water intake by atropine and methylatropine did not differ, also point to the involvement of a peripheral cholinergic system in this type of drinking behaviour. These seemingly contradictory results can be explained if we assume that there are central as well as peripheral inhibitory effects of atropine which (under certain conditions) are not additive. The central component shows up when comparing the effects of small doses of atropine and methylatropine. In that case a small amount of atropine causes a $50 \%$ inhibition by blocking the central part of the system. The peripheral component becomes evident by comparing the effects of the high doses: a $50 \%$ inhibition is caused by a blockade of the peripheral part of the system. Again we are confronted with the fact that the total inhibitory effect of the anticholinergics never amounts to more than $50 \%$. Thus the involvement of a non-cholinergic mechanism in the regulation of water intake caused by a salt hyperosmosis injection can be suggested. 
The stronger inhibitory effect of methylatropine in higher doses cannot be the result of an increase in leakage of methylatropine to central sites because, in experiment II, it was found that the highest dose of methylatropine had the smallest effect. Lastly, here too, it may be possible that the water consumption was reduced because cholinergic mechanisms involved in the production of the behavioural components necessary for drinking were disturbed.

\section{Central administration of atropine and methylatropine}

As expected from earlier experiments (TERPSTRA and SLANGEN, 1972) the inhibition of carbachol-induced drinking by central administration of atropine and methylatropine in the tractus diagonalis was nearly complete. No difference in effect was found between atropine and methylatropine. In this type of drinking, a central cholinergic mechanism seems to play an important part.

The inhibition of deprivation-induced drinking was about the same after centrally administered atropine and methylatropine. Although the inhibition reached only a $20 \%$ level the values obtained differed significantly from the control values for water intake, suggesting a small but real blocking action. Between the inhibitory effect of atropine and methylatropine no difference was found. These results suggest that deprivation-induced drinking, for only a very small part, is mediated by a central cholinergic mechanism.

Centrally administered atropine and methylatropine inhibited the water intake induced by a salt injection also up to a $20 \%$ level. Water intake after treatment with anticholinergic drugs was no different however from water intake after placebo treatment, indicating that a central cholinergic mechanism in this area of the brain is not involved in drinking induced by a salt injection, at least not in the same manner as it is with deprivation-induced drinking.

\section{REFER F.NCFS}

Albe-Fessard, D., Stutinsky, F. and Libouban, S. (1966). Atlas stéréotaxique du diencéphale du rat blanc. Edition du centre national de la Recherche Scientifique, Paris.

Fisher, A. E. and Coury, J. N. (1962). Cholinergic tracing of a central neural circuit underlying the thirst drive. Science, N.Y. 138: 691-693.

FrANCES, H. and $\mathrm{J}_{\mathrm{ACOB}}$, J. (1971). Comparaison des effects de substances cholinergiques et anticholinergiques sur les taux cérébraux d'acétylcholine et sur la motilité chez la souris. Psychopharmacologia 21: 338-352.

GerALD, M. C. and MAICKEL, R. P. (1969). Evidence for peripheral cholinergic components in thirst-induced water consumption. Int. J. Neuropharmac. 8: $337-346$.

Grossman, S. P. (1960). Eating and drinking elicited by direct adrenergic and cholinergic stimulation of the hypothalamus. Science, N.Y. 132: 301-302

Grossman, S. P. (1962a). Direct adrenergic and cholinergic stimulation of hypothalamic mechanisms. Am. J. Physiol. 202: 872-882.

Grossman, S. P. (1962b). Effects of adrenergic and cholinergic blocking agents on hypothalamic mechanisms. Am. J. Physial. 202: 1230-1236.

Grossman, S. P. (1964). Behavioural effects of direct chemical stimulation of central nervous system structures. Int. J. Neuropharmac. 3: 45-58.

HeIse, G. A. and BofF, E. (1971). Stimulant action of $d$-amphetamine in relation to test compartment dimensions and behavioral measure. Neuropharmacology 10: 259-266.

Herz, A., Teschemacher, H., Hofstetter, A. and Kurz, H. (1965). The importance of lipid solubility in the central action of cholinolytic drugs. Int. J. Neuropharmac. 4: 207-218.

JoNGE, H. DE (1964). Inleiding tot de medische statistiek. Verh. Nederl. Instituut Prev. Geneesk., Leiden Vol. 2, pp. $486-487$.

JoNGE, H. DE and WIELENGA, G. (1963). Statistische Methoden voor psychologen en sociologen. 2nd edition, pp. 330. J. B. Wolters, Groningen.

KhAVARI, K. A. and MAICKel, R. P. (1967). Atropine and atropine methyl bromide effects on behaviour of rats. Int. J. Neuropharmac. 6: 301-306. 
KhaVARI, K. A. and Russell, R. W. (1969). Depression of drinking by tertiary and quaternary cholinolytic drugs. Physiol. Behav. 4: 461-463.

KRIKSTONE, B. J. and LevitT, R. A. (1970). Interactions between water deprivation and chemical brain stimulation. J. comp. physiol. Psychol. 71: 334-340.

LEVITT, R. A. and BUERGER, P. B. (1970). Interaction between cholinergic mechanisms and the salt arousal of drinking. Learning and Motivation, $1: 297-303$.

LevitT, R. A. and Fisher, A. E. (1966). Anticholinergic blockade of centrally induced thirst. Science, N.Y. 154: $520-522$.

SteIN, L. (1963). Anticholinergic drugs and the central control of thirst. Science, N.Y. 139: 46-48.

Stein, L. and Seifter, J. (1962). Muscarine synapses in the hypothalamus. Am. J. Physiol. 202: 751-756.

Terpstra, G. K. and Slangen, J. L. (1972). Central blockade of (methyl)-atropine on 'carbachol drinking': a dose-response study. Physiol. Behav. 8: 715-719.

WAYNER, M. J., JR., Ross, J. A. and PRIEN, R. F. (1964). Thirst motivation associated with the salt arousal of drinking. Am. J. Physiol. 206: 369-372. 